\title{
Cyclic changes in phospholipid content and composition in human endometrium during the menstrual cycle
}

\author{
J. L. Montané and B. Pérez-Ballester \\ Instituto de Investigaciones Bioquímicas, Universidad Nacional del Sur, Consejo Nacional de \\ Investigaciones Cientificas y Técnicas, Gorriti 43, 8000 Bahia Blanca, Argentina
}

\begin{abstract}
Summary. A significant increase in total phospholipid content of the endometrium took place during the secretory phase of the human menstrual cycle $(26 \%$ increase from midproliferative to premenstrual stage). The major phospholipid, phosphatidylcholine, was increased by $30 \%$, whereas phosphatidylethanolamine was unchanged. Phosphatidyl-serine and -inositol underwent the largest percentage increases $(40 \%)$. Phosphatidic acid levels were the only ones to decrease $(-52 \%)$, a finding consistent with the role of this lipid as precursor of the increased phospholipids. The changes did not markedly affect phospholipid composition, except for a significant decrease in the proportions of phosphatidate and phosphatidylethanolamine. Arachidonate and eicosatrienoate ( $n-6)$ were the major polyunsaturated fatty acids. $\mathrm{C}_{22}$ tetra-, penta- and hexa-enoic fatty acids of the n-3 and n-4 families were also present in all major endometrial glycerophospholipids throughout the cycle. The mass changes in phospholipids during the cycle occurred without alteration of their fatty acid composition.
\end{abstract}

\section{Introduction}

Morphological and histochemical evidence of alterations in endometrial lipid concentration in different stages of the reproductive cycle was obtained years ago in various animal species. Several metabolic studies followed which established that oestrogenic hormones were responsible for the stimulation of uterine lipid production, and in a review on the subject, Beall (1972) acknowledged that "this increment is probably secondary to an increase in protein (Gorski \& Nicolette, 1963) and RNA (Gorski, 1964)". Such active lipid synthesis must be preceded by the stimulation of various enzymes of lipid metabolism but information about the structure and function of individual lipids and their regulatory enzymes in animals with menstrual cycles is still scarce. Studies on metabolism are needed to ascertain the role and activities of these enzymes during oestrogen-controlled events in the normal cycle and in clinical alterations of reproduction, and compositional studies are a prerequisite for such studies. In this paper the content and composition of phospholipids as well as the fatty acids of major glycerophospholipids in endometrium are analysed.

\section{Materials and Methods}

Endometrial tissue was obtained by "curettage" of normal cyclic women, aged 26 to 32 years, with the informed consent of the women and with the approval of a local ethical committee. Samples were taken at the following stages (Day $0=$ first day of menstruation): mid-proliferative (Days 69), periovulatory (Days 12-14), mid-secretory (Days 18-20) and late secretory or premenstrual (Days 25-28). The length of the cycles ranged between 27 and 30 days. The stage of the cycle was routinely determined on biopsies of samples taken at the same time. The dating of the endometrium was performed following the histological criteria of Dallenbach-Hellweg (1981). Tissue strips were 
rinsed in cold saline $(0.154 \mathrm{M}-\mathrm{NaCl})$ to eliminate residual blood, mucus and tissue debris, and homogenized in chloroform-methanol $(2: 1, v / v)$. Lipid extracts were prepared and washed as described by Folch, Lees \& Sloane-Stanley (1957). Phospholipids were resolved and quantitated according to the procedure of Rouser, Fleischer \& Yamamoto (1970). The protein content of the residues was determined, after lipid extraction, by the method of Lowry, Rosebrough, Farr \& Randall (1951) using bovine serum albumin as standard. To analyse fatty acid composition, lipids were resolved on similar two-dimensional thin-layer chromatography (t.l.c.) plates, the spots viewed under u.v. light after spraying with dichlorofluorescein, and scraped into tubes. Methyl esters were prepared using $14 \%$ boron trifluoride in methanol (Morrison \& Smith, 1964). For phosphatidylethanolamine, methyl esters were separated from dimethylacetals before analysis (Morrison \& Smith, 1964). Fatty acid methyl esters were resolved by gas-liquid chromatography on a $2 \mathrm{~m} \times 2 \mathrm{~mm}$ i.d. stainless-steel column packed with SP-2330 (Supelco, Bellefonte, CA, U.S.A.), using $\mathrm{N}_{2}$ as carrier gas $(30 \mathrm{ml} / \mathrm{min}$ ). A Varian 3700 gas chromatograph equipped with hydrogen flame ionization detectors on line with a CDS-111 integrator (Varian) was used. Injector and detector were at 220 and $240^{\circ} \mathrm{C}$ respectively and the column oven temperature was programmed from 190 to $220^{\circ} \mathrm{C}$, using a $1^{\circ} \mathrm{C}$ linear heating programme. Fatty acids were identified by comparing their retention times with those of standard methyl esters.

\section{Results}

A significant increase in total phospholipid mass was observed in human endometrium during the secretory phase of the cycle (Table 1). Phosphatidylcholine underwent the largest mass increases taking into consideration the fact that it is the major endometrial phospholipid $(50 \%$ of the lipid $\mathrm{P})$, whereas no significant changes in phosphatidylethanolamine mass were observed. This resulted in a significant increase in the ratio of phosphatidylcholine to phosphatidylethanolamine between the first and second halves of the cycle (Table 1). Phosphatidylserine, phosphatidylinositol, and the highly polar compounds remaining at the origin of the t.l.c. plates, underwent the largest increases with respect to controls. The only phospholipid to decrease throughout the cycle was phosphatidic acid. Since the changes were gradual, the most significant differences occurred between the first and the last periods analysed. Most of the differences between consecutive periods (adjacent columns of Table 1) were only marginally significant. The changes in phospholipid mass occurred with small alterations of the percentage composition. The most significant change was the continuous decrease in phosphatidic acid, whose percentage contribution to the lipid $\mathrm{P}$ was $1 \cdot 2,1 \cdot 0$,

Table 1. Changes in phospholipid content in human endometrium during the menstrual cycle

\begin{tabular}{|c|c|c|c|c|c|c|}
\hline \multirow{3}{*}{$\begin{array}{l}\text { Phospholipid } \\
\text { osphatidic acid } \\
\text { losphatidylinositol } \\
\text { hosphatidylserine }\end{array}$} & \multicolumn{6}{|c|}{ Cycle days } \\
\hline & \multirow{2}{*}{$\begin{array}{r}6-9 \\
1.9 \pm 0.4 \\
10.8 \pm 0.9 \\
11.2 \pm 0.7\end{array}$} & \multirow{2}{*}{$\begin{array}{r}12-14 \\
1 \cdot 6 \pm 0 \cdot 2 \\
9 \cdot 6 \pm 0 \cdot 9 \\
11 \cdot 3 \pm 0 \cdot 7\end{array}$} & \multicolumn{2}{|c|}{$18-20$} & \multicolumn{2}{|c|}{$25-28$} \\
\hline & & & $\begin{array}{r}1 \cdot 3 \pm 0 \cdot 1^{*} \\
12 \cdot 1 \pm 0 \cdot 6^{*} \\
14 \cdot 1 \pm 1 \cdot 5^{*}\end{array}$ & $\begin{array}{r}(-30.5) \\
(12.0) \\
(25 \cdot 9)\end{array}$ & $\begin{array}{r}0 \cdot 9 \pm 0 \cdot 3^{*} \\
15 \cdot 2 \pm 2 \cdot 8^{*} \\
16 \cdot 1 \pm 2 \cdot 0^{*}\end{array}$ & $\begin{array}{r}(-51 \cdot 9) \\
(40 \cdot 7) \\
(43 \cdot 7)\end{array}$ \\
\hline $\begin{array}{l}\text { Phosphatidylcholine (A) } \\
\text { Phosphatidylethanolamine (B) } \\
\text { Sphingomyelin } \\
\text { Diphosphatidylglycerol } \\
\text { Origin }\end{array}$ & $\begin{array}{r}79 \cdot 6 \pm 5 \cdot 7 \\
39 \cdot 9 \pm 2 \cdot 1 \\
17 \cdot 5 \pm 2 \cdot 1 \\
1.9 \pm 0 \cdot 4 \\
1 \cdot 4 \pm 0 \cdot 3\end{array}$ & $\begin{array}{r}86 \cdot 1 \pm 9 \cdot 9 \\
43 \cdot 6 \pm 4 \cdot 1 \\
13 \cdot 6 \pm 1 \cdot 7 \\
2 \cdot 0 \pm 0 \cdot 3 \\
1 \cdot 2 \pm 0 \cdot 2\end{array}$ & $\begin{array}{l}91 \cdot 8 \pm 16 \cdot 9 \\
38 \cdot 2 \pm 3 \cdot 3 \\
19 \cdot 2 \pm 2 \cdot 8 \\
3 \cdot 1 \pm 0 \cdot 3^{*} \\
2 \cdot 3 \pm 0 \cdot 3^{*}\end{array}$ & $\begin{array}{r}(15 \cdot 3) \\
(-4 \cdot 2) \\
(9 \cdot 7) \\
(63 \cdot 1) \\
(64 \cdot 3)\end{array}$ & $\begin{array}{c}104 \cdot 4 \pm 10 \cdot 4^{*} \\
43 \cdot 0 \pm 5 \cdot 4 \\
21 \cdot 0 \pm 1 \cdot 4^{*} \\
2 \cdot 3 \pm 0 \cdot 6 \\
3 \cdot 6 \pm 1 \cdot 1^{*}\end{array}$ & $\begin{array}{r}(31 \cdot 1) \\
(7 \cdot 7) \\
(20 \cdot 0) \\
(21 \cdot 0) \\
(157 \cdot 1)\end{array}$ \\
\hline $\begin{array}{l}\text { Total phospholipid } \\
\text { A/B ratio }\end{array}$ & $\begin{array}{l}161.3 \pm 4.8 \\
1.95 \pm 0.06\end{array}$ & $\begin{array}{r}167 \cdot 7 \pm 16 \cdot 1 \\
1.97 \pm 0 \cdot 14\end{array}$ & $\begin{array}{r}183.9 \pm 16 \cdot 1^{*} \\
2.41 \pm 0.46^{*}\end{array}$ & $(14 \cdot 0)$ & $\begin{aligned} 203.2 & \pm 29.0^{*} \\
2.44 & \pm 0.30^{*}\end{aligned}$ & $(25.9)$ \\
\hline
\end{tabular}

Content is expressed as $\mathbf{n m o l}$ lipid $\mathbf{P} / \mathbf{m g}$ protein, with mean values \pm s.d. from $5-11$ individual samples.

Values in parentheses indicate mean percentage changes with respect to the Day 6-9 samples, taken as controls.

* Statistically significant difference (by Student's $t$ test) in lipid content with respect to controls $(P<0.05)$. 


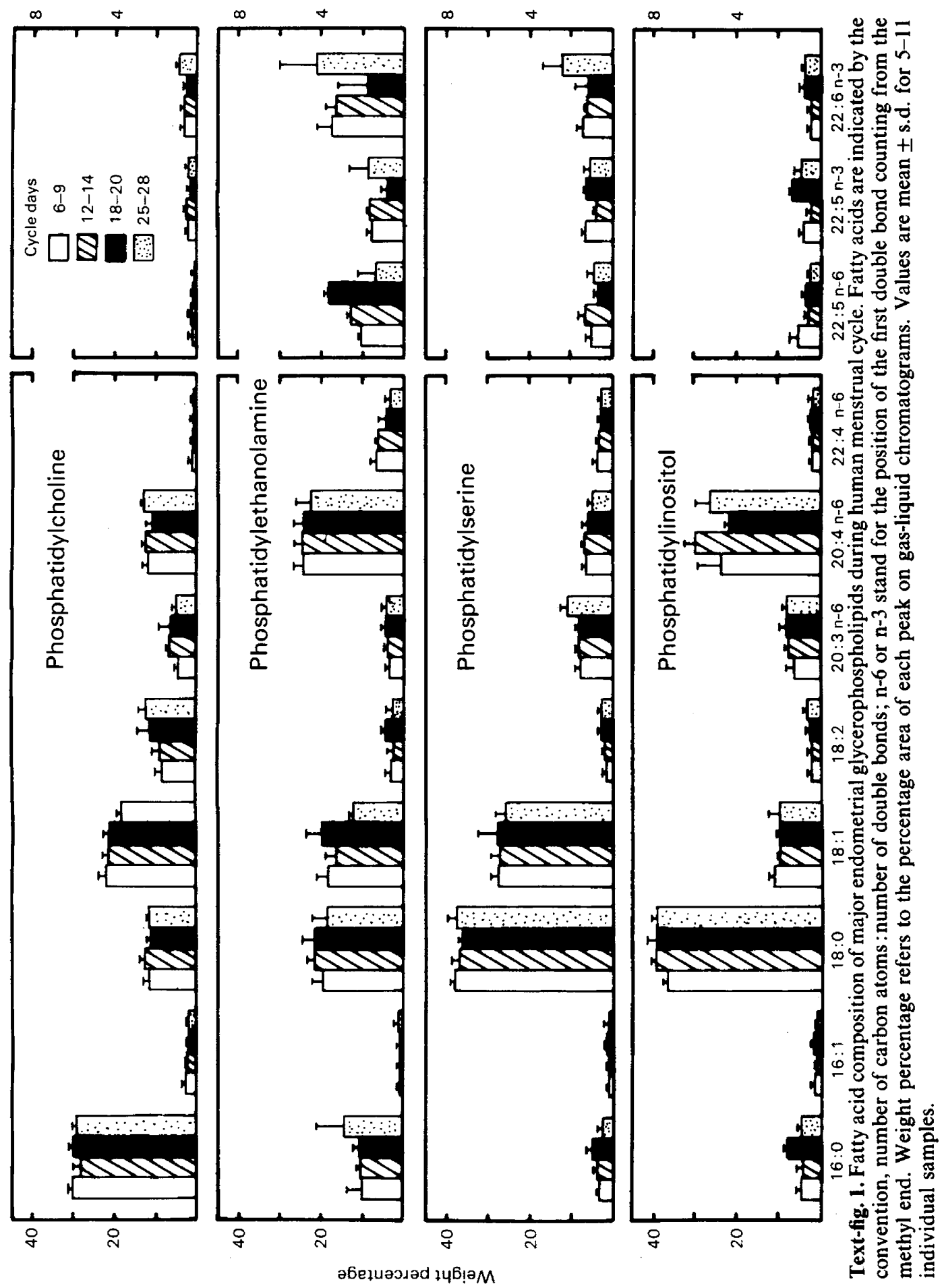


0.7 and $0.4 \%$ for the four stages shown in Table 1 . The proportion of phosphatidylethanolamine also showed a significant decrease (from 25 to $21 \%$ ) between the first and second halves of the cycle, as can be calculated from Table 1 . The changes in phospholipid mass occurred without significant alterations of the fatty acid composition (Text-fig. 1). The major saturated fatty acid of phosphatidylcholine was palmitate $(16: 0)$ whereas stearate $(18: 0)$ predominated in phosphatidylethanolamine, -serine and -inositol. Oleate $(18: 1)$ was the major monoene and arachidonate $(20: 4)$ was the major polyunsaturated fatty acid in all four glycerophospholipids. Polyenes containing 22 carbon atoms of the n-3 and n-6 families were also present in endometrial phospholipids.

\section{Discussion}

The results in this paper show that a gradual increase in phospholipid mass occurs in human endometrium during the menstrual cycle. This is consistent with the net enhancement of lipid synthesis which reportedly follows oestrogen stimulation (Spooner \& Gorski, 1972). Our data indicate that such stimulation does not involve all phospholipids to the same extent, and suggest the concerted activity of various enzymes of lipid metabolism throughout the cycle. The significant decrease in phosphatidate levels and increase in phosphatidylcholine and phosphatidylinositol are consistent with the operation of de-novo lipid biosynthetic pathways in human endometrium, since phosphatidate is the common precursor of both phospholipids through metabolic routes involving cytidine diphosphate diacylglycerol and cytidine diphosphate choline, respectively (Bell \& Coleman, 1980). The synthesis of phosphatidylcholine through cytidine diphosphate cholinediacylglycerol transferase has been shown to be stimulated by oestrogen in the rat uterus (Spooner \& Gorski, 1972).

The unchanged levels of phosphatidylethanolamine are unlikely to reflect a metabolic inertness of this phospholipid but rather suggest its utilization in the synthesis of other glycerophospholipids, and hence the possibility that other enzymes of lipid metabolism are expressed. For example, the presence of $\mathrm{N}$-methyltransferases could account for part of the increases in phosphatidylcholine using phosphatidylethanolamine as substrate. $\left[2-{ }^{14} \mathrm{C}\right]$ Ethanolamine incorporation into phosphatidylcholine has been shown to be stimulated by oestrogen in the rat uterus (Nishigori \& Aizawa, 1968). Moreover, base exchange reactions replacing choline or serine for ethanolamine could also be involved. The $\mathrm{Ca}^{2+}$-stimulated serine exchange reaction using phosphatidylethanolamine as substrate is the best known metabolic pattern for phosphatidylserine synthesis in mammals (Bjerve, 1973).

Both the polar head and the acyl chains of glycerophospholipids are known to determine the degree of fluidity of biological membranes. Highly fluid membranes are characteristic of metabolically dynamic tissues such as the brain and the liver, and human endometrium necessarily falls into this category. It is well established that an increase in the phosphatidylcholine/phosphatidylethanolamine ratio increases the fluidity of membranes. Changes in membrane biophysical properties are likely to occur during the second half of the cycle which could be related to physiological events such as blastocyst implantation and early embryonic development.

The striking constancy of glycerophospholipid fatty acid composition throughout the cycle (Text-fig. 1) may reflect the fact that a steady supply of fatty acids from the circulation occurs. However, plasma lipids are not the only source of fatty acids for endometrial lipids, as suggested by the relative enrichment in polyunsaturated fatty acids (e.g. arachidonic) in uterine lipids as compared to blood (Leaver \& Poyser, 1981) and by the fact that human endometrium actively incorporates $\left[1{ }^{-14} \mathrm{C}\right]$ acetate into polar and neutral glycerolipids (Merrill \& Werthessen, 1966). The presence of 22 carbon tetra-, penta-, and hexa-enoic fatty acids suggests that elongating enzymes and desaturases are operative in endometrial tissue since these fatty acids are in exceedingly low concentrations in plasma lipids. Arachidonate and eicosatrienoate (n-6) were the major polyenoic acyl 
groups of human endometrial phospholipids. Phosphatidyl-choline and -ethanolamine contribute almost equally to the total arachidonate in endometrium, since although the percentage of arachidonate is twice as low in phosphatidylcholine than in phosphatidylethanolamine, the content of the former is double that of the latter. As in the guinea-pig uterus (Leaver \& Poyser, 1981) 80\% of the total arachidonate in endometrium is esterified to these two phospholipids. Phosphatidylserine and phosphatidylinositol contribute to 4 and $12 \%$, respectively, of the total arachidonate. The lipid source of free arachidonate for prostaglandin synthesis remains to be established. Endometrium has been shown to be the major site of prostaglandin synthesis in the uterus (Thorburn \& Challis, 1979) and prostaglandin synthetase has been detected in various subcellular fractions of endometrium (Wlodawer, Kindahl \& Hamberg, 1976). The release of arachidonic and eicosatrienoic acids from endometrial glycerophospholipids is a prerequisite for prostaglandin formation. That such a mechanism operates in human endometrium is suggested by the fact that incubation of this tissue with phospholipase $\mathrm{A}_{2}$ stimulates prostaglandin biosynthesis (Sykes, Williams \& Rogers, 1975).

The reported changes in lipid mass during the menstrual cycle may be related to the differentiation of endometrial tissue. The obvious increase in the phospholipid to protein ratio shown in Table 1 is consistent with the idea that an active membranogenesis takes place. It is suggested that human endometrium contains the potential to synthesize and activate all enzymes of lipid metabolism known to operate in differentiated tissues.

J.L.M. was a holder of a research fellowship from the "Fundación para la Investigación Cientifica y la Cultura", Bahía Blanca. We thank Dr H. Maturi for the histological studies of the samples, and Dr M. I. Aveldaño and Dr F. J. Barrantes for collaboration in the preparation of the manuscript.

\section{References}

Beall, J.R. (1972) Uterine lipid metabolism-a review of the literature. Comp. Biochem. Physiol. 42, 175-195.

Bell, R. \& Coleman, R. (1980) Enzymes of glycerolipid synthesis in eukaryotes. Ann. Rev. Biochem. 49, 459487.

Bjerve, K.S. (1973) The $\mathrm{Ca}^{++}$dependent biosynthesis of lecithin, phosphatidylethanolamine, and phosphatidylserine in rat liver subcellular particles. Biochim. Biophys. Acta 296, 549-562.

Dallenbach-Hellweg, G. (1981) Histopathology of the Endometrium. Springer-Verlag, Berlin.

Folch, J., Lees, M. \& Sloane-Stanley, G.H. (1957) A simple method for the isolation and purification of total lipids from animal tissues. J. biol. Chem. 226, 497-509.

Gorski, J. (1964) Early estrogen effects on the activity of uterine ribonucleic acid polymerase. $J$. biol. Chem. 239, 889-892.

Gorski, J. \& Nicolette, J. (1963) Early estrogen effects on newly synthesized RNA and phospholipid in subcellular fractions of rat uteri. Archs Biochem. Biophys. 103, 418-423.

Leaver, H. \& Poyser, N. (1981) Distribution of arachidonic acid and other fatty acids in the lipids of guinea-pig uterus and plasma in relation to uterine prostaglandin synthesis. J. Reprod. Fert. 61, 325-333.

Lowry, O.H., Rosebrough, N.J., Farr, A.L. \& Randall, R.J. (1951) Protein measurement with the Folin phenol reagent. J. biol. Chem. 193, 265-275.
Merrill, J. \& Werthessen, N. (1966) Lipid biosynthesis by human endometrium. Am. J. Obstet. Gynec. 96, 619630.

Morrison, W.R. \& Smith, L.M. (1964) Preparation of fatty acid methyl esters and dimethylacetals from lipids with boron fluoride-methanol. J. Lipid Res. 5, $600-608$

Nishigori, H. \& Aizawa, Y. (1968) Effect of estradiol on phospholipid biosynthesis from choline-1,2-14 $\mathrm{C}$, ethanolamine-2-14 $\mathrm{C}$, and serine- $-3^{-14} \mathrm{C}$ in rat uterus and liver. Jap. J. Pharmacol. 18, 397-405.

Rouser, G., Fleischer, S. \& Yamamoto, A. (1970) Two dimensional thin layer chromatographic separation of polar lipids and determination of phospholipids by phosphorous analysis of spots. Lipids 5, 494-496.

Spooner, P. \& Gorski, J. (1972) Early estrogen effects on lipid metabolism in the rat uterus. Endocrinology 91, 1273-1283.

Sykes, J.A.C., Williams, K.I. \& Rogers, A.F. (1975) Prostaglandin production and metabolism by homogenates of pregnant human deciduum and myometrium. J. Endocr. 64, 18-19.

Thorburn, G.D. \& Challis, J.R.G. (1979) Endocrine control of parturition. Physiol. Rev. 59, 863-918.

Wlodawer, P., Kindahl, H. \& Hamberg, M. (1976) Biosynthesis of prostaglandins from arachidonic acid and prostaglandin endoperoxides in the uterus. Biochim. Biophys. Acta 431, 603-614. 